\title{
LA LIBERTAD RELIGIOSA ANTE LA SUPREMA CORTE. COMENTARIO AL AMPARO EN REVISIÓN 1595/2006
}

\author{
Miguel CARBONELL
}

Si es verdad que puede decirse que la Suprema Corte de Justicia de la Nación (SCJN) se ha ocupado en pocas ocasiones de aspectos de fondo relativos a los derechos fundamentales, ${ }^{1}$ lo es todavía más respecto de cierto tipo de derechos cuyo tratamiento jurisdiccional ha estado completamente ausente de la práctica de la jurisdicción constitucional. Es el caso de la libertad religiosa, que ha aparecido muy poco o prácticamente nada en las sentencias de la Corte. ${ }^{2}$

Por eso es que la sentencia del amparo en revisión 1595/2006 tiene mucho interés, pues a partir de su resolución contamos con importantes definiciones de la Primera Sala de la SCJN sobre el tema.

Además, la sentencia mencionada es interesante también por cuestiones de orden formal, pues se trata de una resolución modélica, tanto por la forma tan pulcra en que se desarrolla la argumentación, como por la brevedad de su texto, que apenas supera las 30 páginas. Seguramente

1 Véase el argumento que, en este sentido, construyen Ana Laura Magaloni y Arturo Zaldívar, "El ciudadano olvidado", Nexos, México, núm. 342, junio de 2006.

2 Hay, sin embargo, algunas sentencias de tribunales colegiados que sin bien no se refieren directamente a la libertad religiosa sí tratan aspectos relacionados; me refiero a algunas sentencias de los años noventa del siglo pasado en los que se planteaba por parte de algunos particulares la inconstitucionalidad de las expulsiones de menores de edad que acudían a escuelas públicas por negarse a saludar a la bandera y cantar el himno nacional. Dichos menores profesaban una creencia religiosa que no les permitía participar en ese tipo de ceremonias y eran por ese motivo expulsados de las escuelas primarias públicas. Sobre el tema, véase Martínez Torrón, Javier, "Los testigos de Jehová y la cuestión de los honores a la bandera en México", Gaceta de la Comisión Nacional de los Derechos Humanos, México, núm. 117, abril de 2000. 
quienes se dedican a darle seguimiento a las sentencias de la Corte, desearían que todas ellas fueran tan legibles y tuvieran la claridad y la brevedad de la que se comenta. No es extraño que su autor haya sido José Ramón Cossío, que es el ministro más preparado de la Corte y que tiene un amplio entrenamiento en la redacción de textos jurídicos a la vez claros y profundos.

El amparo en revisión 1595/2006 se refería a la posible inconstitucionalidad del Bando Municipal de la ciudad de Toluca, que en una de las fracciones de su artículo 123 disponía una sanción de multa para la persona que "Sin permiso, pegue, cuelgue, distribuya o pinte propaganda de carácter comercial o de cualquier otro tipo en edificios públicos, portales, postes de alumbrado público....".

Stephen Orla Searfoss distribuyó dos folletos en una calle de la ciudad de Toluca; en uno de ellos se invitaba a un concierto gratuito y en el otro se contenían fragmentos del libro sagrado de una determinada confesión religiosa, la cual tiene registro legal como iglesia en México, de acuerdo a lo que exige el artículo 130 de la Constitución y su ley reglamentaria. El quejoso argumentaba que la previsión del Bando Municipal violaba su derecho de libertad de expresión, de libertad de imprenta y de libertad religiosa, los cuales están contenidos en los artículos 6o., 7o. y 24, todos de la Constitución mexicana.

La sentencia construye su línea argumental a partir de tres distintos niveles de análisis: primero hace una reconstrucción conceptual de los derechos involucrados en el caso concreto y de su alcance respectivo; luego establece los requisitos que deben cumplir las normas infraconstitucionales que los desarrollen para ser congruentes con lo que dispone la carta magna; finalmente se analiza el precepto del Bando Municipal impugnado para ver si es consistente o no con las anteriores bases analíticas.

También, la sentencia anuncia desde el principio de su considerando quinto que la norma en cuestión no es compatible por el texto constitucional, ya que la forma en que está redactada permite sancionar actividades que en algunos aspectos están protegidas por normas de derechos fundamentales.

En primer lugar, la Corte considera inconstitucional el requisito consistente en tener que solicitar permiso para ejercer actividades protegidas por un derecho fundamental; en virtud de que los derechos en cuestión son las libertades de expresión e imprenta, dicho requisito se constituye 
como una especie de "censura previa", la cual desde luego está prohibida no sólo por las normas constitucionales mexicanas, sino también por diversos tratados internacionales de derechos humanos. Este argumento es completamente cierto; las normas infraconstitucionales no pueden exigir, sin más, permiso de tipo alguno para ejercer los derechos fundamentales, pues ese requisito puede constituirse como un elemento inhibitorio para que los particulares ejerzan a plenitud y sin cortapisas sus derechos.

La exigencia de un permiso podrá darse solamente cuando se trate de una forma de lograr la compatibilización entre derechos fundamentales o cuando existan elementos empíricos suficientes para permitirnos concluir que el permiso puede ser un instrumento adecuado de carácter preventivo para evitar la violación de un derecho (por ejemplo, el derecho al medio ambiente, cuando pueda objetivamente ser afectado por el ejercicio del derecho de propiedad o por el de la libertad de trabajo).

La Corte es precisa al señalar que la prohibición de censura previa "implica que el Estado no puede someter las actividades expresivas o comunicativas de los particulares a la necesidad de solicitar previamente un permiso a la autoridad”. Esta afirmación es muy importante. Cabría preguntarse si la lógica en que se sustenta podría aplicarse a derechos distintos a la libertad de expresión o a la libertad de imprenta. Por ejemplo, ¿viola también la Constitución una norma reglamentaria o legislativa que obliga a los particulares a pedir permiso previo antes de ejercer en cualquiera de sus manifestaciones la libertad de profesión, oficio o industria prevista en el artículo 5o. constitucional?

Además, la Sala argumenta que el Bando Municipal no establece lineamiento alguno para guiar el criterio de la autoridad administrativa competente para imponer la multa, lo que puede generar actividades administrativas arbitrarias. Lo que señala la Sala es, en efecto, sumamente grave, pero lo es todavía más si se toma en cuenta que la norma en cuestión es de rango reglamentario, no legislativo. Las autoridades emisoras de normas infralegales no deben tener tan abiertos los márgenes de regulación, sobre todo cuando tal regulación puede tener incidencia en la esfera de ejercicio de los derechos fundamentales.

Respecto de los derechos en juego, la sentencia comienza enunciando el alcance de la libertad de expresión, para cuyo efecto cita el artículo 6o. de la Constitución mexicana y el artículo 13 de la Convención Americana de Derechos Humanos. La Corte concluye de su análisis que la liber- 
tad de expresión no es solamente importante en sí misma, sino también en virtud de que es una herramienta para ejercer otros derechos, como el derecho de asociación y reunión; el derecho de petición y los derechos de participación política. Este carácter instrumental de la libertad de expresión supone un elemento esencial "en la dinámica de una democracia representativa", dice la sentencia.

Agrega la Sala que cuando un tribunal resuelve un caso de libertad de expresión o de libertad de imprenta no solamente afecta al caso concreto que se ventila, sino que su decisión se proyecta al conjunto del país, en tanto el criterio judicial contribuye a determinar el grado en que quedará asegurada la circulación de noticias, ideas y opiniones, así como el acceso a la información de toda la sociedad. ${ }^{3}$ De nuevo, este razonamiento de la Corte es impecable; ojalá los demás jueces del país tuvieran claro lo anterior (de hecho, ojalá lo hubieran tenido claro los mismos ministros cuando resolvieron otros casos de libertad de expresión en el pasado, en los que cometieron enormes y clamorosos errores). ${ }^{4}$

Respecto de la libertad religiosa, la Corte señala que tal libertad tiene dos dimensiones: una interna y otra externa. La primera la asocian los ministros con la libertad ideológica, la cual es considerada inexistente por algunos teóricos. ${ }^{5}$

La vertiente interna de la libertad religiosa es prácticamente ilimitada, señala la sentencia, ya que el Estado no pueden intervenir en lo que se desarrolla en el ámbito íntimo de cada individuo: su pensamiento. La misma vertiente faculta a toda persona para desarrollar las creencias religiosas o ideológicas que considere oportuno, pero protege también la posibilidad de que no se adhiera a ninguna confesión religiosa. Sucede lo

3 Las palabras de la sentencia son las siguientes: "cada vez que un tribunal decide un caso de libertad de expresión o imprenta, está afectando no solamente las pretensiones de las partes en un litigio concreto, sino también el grado al que en un país quedará asegurada la libre circulación de noticias, ideas y opiniones, así como el más amplio acceso a la información por parte de la sociedad en su conjunto, todo ello condición indispensable para el adecuado funcionamiento de la democracia representativa".

4 Carbonell, Miguel, "Ultrajando a la Constitución. La Suprema Corte contra la libertad de expresión”, Isonomía, México, núm. 24, abril de 2006, pp. 171 y ss.

5 Para la Corte, "La dimensión o la faceta interna de la libertad religiosa se relaciona íntimamente con la libertad ideológica, y aunque es difícil de definir de un modo que sea general y a la vez útil, atiende a la capacidad de los individuos para desarrollar y actuar de conformidad con una particular visión del mundo en la que quede definida la relación del hombre con lo divino". 
mismo con otros derechos de libertad, en los que el titular puede decidir ejercerlos o no. La propia Corte ha señalado desde hace unos años que, por poner un ejemplo, la libertad de asociación comporta la posibilidad de ingresar en una asociación, salir de ella o nunca formar parte de la misma; las tres dimensiones estarían protegidas por la libertad asociativa, sin que un particular pueda ser obligado (en términos generales) a ejercer o llevar a cabo alguna de ellas. En efecto, al estudiar la constitucionalidad del artículo 5o. de la Ley de las Cámaras de Comercio y de las de Industria que preveía la afiliación obligatoria para cierto género de comerciantes, la Corte afirmó que la esfera de protección derivada del artículo 9o. constitucional puede operar en tres posibles direcciones:

10. Derecho de asociarse formando una organización o incorporándose a una ya existente; 20 . Derecho a permanecer en la asociación o a renunciar a ella; y 3o. Derecho de no asociarse. Correlativamente, la autoridad no podrá prohibir que el particular se asocie; no podrá restringir su derecho a permanecer en la asociación o a renunciar a ella, ni, tampoco, podrá obligarlo a asociarse. Consecuentemente, el artículo 5o. de la Ley de las Cámaras de Comercio y de las de Industria al imponer la obligación a los comerciantes e industriales a afiliarse a la Cámara correspondiente, viola la libertad de asociación establecida por el artículo 9o. constitucional. ${ }^{6}$

La libertad religiosa tiene también una proyección exterior, que se expresa en multitud de posibilidades, entre las que se encuentran el desarrollo de actos de culto público, como los ritos, ceremonias y reuniones propias de la creencia religiosa que se profese. ${ }^{7}$ Pero no todos los actos protegidos por la libertad religiosa prevista en el artículo 24 constitucional son actos de culto público; hay otros que también están cubiertos por la previsión constitucional. Para la Corte, tal es el caso de la actividad realizada por Stephen Orla, consistente en la distribución de impresos dirigidos a dar a conocer la doctrina religiosa de una determinada iglesia.

Al confrontar las anteriores consideraciones de carácter general respecto de los derechos fundamentales relevantes para el caso concreto con

6 Semanario Judicial de la Federación, novena época, octubre de 1995, t. 11, p. 5.

7 La sentencia define los actos de culto público como los que están "específicamente orientados a desarrollar de manera colectiva los ritos, ceremonias y conductas que las diferentes religiones reconocen como manifestaciones institucionalizadas o formalizadas de su fe religiosa, definidas y gobernadas por reglas prestablecidas por ellas". 
el artículo 123 del Bando Municipal, la Corte afirma que alguna de las prohibiciones establecidas por la norma en cuestión abarcan actividades permitidas y protegidas por normas de derecho fundamental. La norma municipal es "sobre-inclusiva" en su regulación, abarcando actos cuyo ejercicio debería quedar exento de cualquier sanción, del tipo que sea.

Las actividades prohibidas por la norma municipal son muy heterogéneas y no pueden ser agrupadas en una misma regulación, a riesgo de incluir actividades que deben ser permitidas, pues son objeto de tutela constitucional. La Corte señala que no es lo mismo pegar publicidad en el mobiliario urbano que circular por una calle y distribuir escritos de promoción religiosa. En un caso puede haber una afectación objetiva a bienes públicos; en el otro no se da dicha afectación más allá de la natural ocupación temporal de la calle en cuestión, sin que esa ocupación impida por la misma calle la circulación de otras personas, las cuales pueden hacer un uso idéntico de la calle. ${ }^{8}$

Aunque no lo dice expresamente, se puede concluir que la Corte admite implícitamente que hay algunos tipos de expresiones que tienen más valor que otros. Por ejemplo, las expresiones comerciales podrían ser objeto de una regulación más intensa que las expresiones religiosas o políticas. Esto es algo que aceptan pacíficamente tanto la jurisprudencia comparada en materia de libertad de expresión, como los mejores teóricos que han estudiado el tema. ${ }^{9}$ Las expresiones religiosas o políticas comportan la protección de valores esenciales para el Estado democrático, en tanto suponen el ejercicio no solamente de la libertad de expresión, sino (instrumentalmente) de otros derechos; por esta razón es que merecen ser protegidas con mayor energía, superior a la que se destina a la tutela de

8 Las palabras de la sentencia son: "Ninguna analogía puede trazarse entre las actividades de pegar o colgar documentos, o pintar, en bienes de dominio público, y la muy distinta actividad de circular o pasear por la calle y repartir a la ciudadanía un texto que contiene un documento religioso y una invitación a asistir a un concierto. Las primeras implican efectivamente el uso de superficies de uso público, y un uso que no sólo implica un desgaste y envejecimiento de las mismas, sino también una limitación a la posibilidad de que otros ciudadanos puedan hacer de ellas un uso idéntico; de manera que la acción coordinadora y eventualmente proscriptora o sancionadora que el Estado pueda desplegar no puede ser, de entrada, descartada".

9 Véase por ejemplo Sunstein, Cass R., Democracy and the Problem of Free Speech, Nueva York, The Free Press, 1995. El tratamiento de este tipo de asuntos en la Suprema Corte de los Estados Unidos comienza en 1942, con el caso Valentine vs. Chrestensen, al que siguen un buen número de sentencias sobre el tema. 
las expresiones de contenido comercial (como las vinculadas por la publicidad).

En materia de derechos fundamentales la SCJN ha cometido en los últimos años importantes pifias. Por ello ha sido objeto de críticas en los medios de comunicación y en las publicaciones especializadas en materia jurídica. La mayoría de tales críticas (por cuanto se dirigen a criterios judiciales públicos y, como tales, absolutamente discutibles) han sido muy merecidas y necesarias. Sin embargo, sin demérito de lo anterior, también resulta necesario reconocer que, en algunas ocasiones, la Corte emite buenas sentencias. Es el caso de la sentencia del amparo en revisión $1595 / 2006$. El pronunciamiento judicial referido es impecable en el fondo y en la forma. Original en sus planteamientos, pulcro desde el punto de vista lingüístico, progresista en su análisis de fondo de los derechos de libertad de expresión, de imprenta y de libertad religiosa. Desde luego, puestos a buscarle defectos se le podrían señalar algunos menores, ${ }^{10} \sin$ que alcancen a empañar sus aciertos. Habla muy bien de los cinco ministros que conforman la Primera Sala que el proyecto haya sido aprobado por unanimidad. Ojalá veamos en el futuro muchas sentencias como la que hemos analizado brevemente, las cuales sin duda serán muy aplaudidas y reconocidas por los abogados mexicanos.

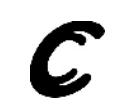

10 Por ejemplo, la débil fundamentación normativa de la libertad religiosa, puesto que el análisis de la Corte únicamente se basa en el artículo 24 constitucional, habiendo multiplicidad de normas internacionales (incluyendo jurisprudencia) que protegen dicha libertad. También podrían haberse añadido algunas notas de derecho comparado, por ejemplo en libertad de expresión y de nuevo en el tema de la libertad religiosa. 